\title{
The International Development of Open Access Publishing: A Comparative Empirical Analysis Over Seven World Regions and Nine Academic Disciplines
}

\author{
Marton Demeter ${ }^{1} \cdot$ Agnes Jele $^{2} \cdot$ Zsolt Balázs Major $^{2}$
}

Accepted: 12 May 2021 / Published online: 25 May 2021

(c) The Author(s) 2021

\begin{abstract}
This paper offers a cross-country and cross-disciplinary analysis of the development of open access publishing from 2000 to 2019. Through an analysis of seven world regions and nine scholarly fields, we found that, while the overall share of open access journals has increased significantly over the last two decades, there are important differences across both the analyzed world regions and disciplines. We also found that, with the exception of neuroscience, the proportion of open access journals is considerably lower among the journals ranked in the Q1 quartile of Scopus than in the general field. We also offer a model that explains the development of open access publishing trends on different disciplinary and geographical levels.
\end{abstract}

Keywords Open access publishing · Academic journals · Geopolitics of publishing · Publishing trends

\section{Introduction}

The field of scholarly publishing encountered the open access phenomenon [3] at the beginning of the twenty-first century, and the movement has been fueled by both technological revolution and scholarly pressure [19]. Due to widespread internet penetration, the growing prevalence of web-based knowledge transfer services and the communication revolution $[2,10,23]$, new information technology has provided

Marton Demeter

Demeter.Marton@uni-nke.hu

Agnes Jele

agnes.jele@uni-corvinus.hu

Zsolt Balázs Major

majorzsb@icloud.com

1 University of Public Service, 2 Ludovika Square, 1083 Budapest, Hungary

2 Corvinus University of Budapest, Budapest, Hungary 
an opportunity for developing innovative and enabling open access publishing models [42]. Over the space of a few years, this communication revolution has brought a real paradigm shift in the sharing of academic knowledge, and the internet has provided new platforms for both the production and the dissemination of knowledge [15]. While open access publishing models first emerged as experimental models, it took only a few years for them to become mainstream approaches to delivering scientific knowledge [37]. Over the last two decades, legions of open access models have been developed, from which the most popular models are the gold, hybrid, green and diamond models [21]. While it is characteristic of all open access publication forms that the materials published are free to access and read online [22], there are fundamental differences between open access models regarding other aspects of publication. In the case of the golden model, all papers are published with open access and authors (or their institutions) must pay an article processing charge that varies by disciplines, publishers, geopolitical locations and even the prestige of the journals [13]. Green open access models [5, 29] allow authors to upload their papers to freely accessible research depositories (typically, after an embargo period), while hybrid models generally publish in a classical, prescription-based model, but, if they pay an author processing charge, authors can choose the open access option as well $[4,30]$. Finally, diamond open access models provide free open access to both authors and readers $[12,16,35]$.

The history behind open access has been widely discussed in the literature [17, 25, 26, 38]. After World War II, the Western world (especially the U.S.), experienced a significant growth of government investment in academic research that led to an unprecedented increase in the number of scholarly publications [27]. The skyrocketing number of research papers, despite the communication revolution enabling research papers to be made available online at considerably lower cost, was accompanied by an exponential rise in publication purchasing prices $[1,7,20]$. As a consequence, several institutions, associations and new initiatives started to argue that the traditional academic publishing industry should be dramatically reformed, and new technological innovations should be used to promote open science built on free access to scholarly knowledge.

The early 2000s were the beginning of the so-called open access era [11]. In 2001, the Open Society Institution convened the Budapest Conference with a focus on the possibilities of open access publishing [15], which was followed by the Budapest Open Access Initiative statement in 2002 [26]. Basically, the Budapest Statement considered the gold and the green open access models, and the strategies of this initiative were followed by many subsequent statements such as the Bethesda Statement on Open Access Publishing in 2003, the Berlin Declaration on Open Access to Knowledge [32], or the initiatives of the Open Access Scholarly Publishers Association in 2008 [26, 43, 44]. Hybrid open access journal publishing deals were concluded with major publishers such as Springer Nature and Wiley though the Project DEAL, and more recently the Plan S initiative [38] requires all publicly funded authors to publish their results on an open access platform [28, 38]. Specifically, in the European context, open access publishing has been part of the academic agenda since 2006, and the Lisbon Treaty (2007) clearly emphasized the European Union's commitment to open access publishing. The Horizon 2020 program made it 
mandatory to publish publicly funded research open access, project proposals submitted to the European Research Council's tenders should indicate the planned open access costs, and Science Europe [39] drafted minimum standards for open access publishing services [26].

Underlying the abovementioned strategies and policies, there is a seemingly self-evident conviction of the academic community to the effect that open access publication maximizes the benefits of scholarly research for both the academic field and the public $[22,45]$. Economic, social and academic benefits are extensively discussed in the literature [22], with a specific emphasis on the growth in readership and impact due to open access publishing [40, 41]. Addressing the most important public debates on open access, Kingsley [24] analyzed several critical narratives around open access, from which most criticism relates to the quality of open access journals. Kingsley argued that-barring clear-cut cases of malpractice by predatory journals - open access journals can be of excellent quality and authors need not necessarily choose between esteem and sharing, or between quality and accessibility; indeed, many authors publish their best works in open access journals. As contrasted with several authors who found open access journals to be less prestigious or even that they engage in unethical practices $[6,8,33]$, Kingsley argued that the quality of a journal is defined by its editorial policy and authorship, not its publishing model [24].

Others argue that, beyond the question of quality, disciplinary and geopolitical differences also have an impact on open access policies. On the one hand, healthrelated disciplines such as biomedical sciences have a considerably higher percentage of open access publication than other academic fields [34, 36], due to funders' mandates and high public interest $[9,22]$. On the other hand, there are geopolitical regions such as Ibero-America where open access publishing has a long tradition and where it is part of the national academic strategy. According to Scimago, the number of Ibero-American journals has increased from zero to 45 over the past 20 years, and the share of Ibero-American journals in Scopus is now slightly over $10 \%$ in several scientific fields. Moreover, the pace of the growth of Ibero-American journals is considerably faster than the overall growth of the field [14].

Despite the legion of research papers that focus on the history and growth of the open access publishing system, and the many analyses of the publishing patterns in specific countries and disciplines, we still lack a coherent picture of the global development of open access journals over the last two decades. Moreover, we have only limited empirical evidence on how the prestige factors of journals relate to open access publishing trends. In addition, we still need a comprehensive analysis that aims to explore existing differences between various disciplines and geographical locations in terms of their open access patterns. In accordance with these specific knowledge gaps, our present study aims to analyze the development of open access publication over the last two decades across nine disciplines and seven world regions. In order to explore these existing knowledge gaps in the literature of open access publishing, we developed three research questions.

RQ1 What is the general trend in open access publishing over disciplines between 2000 and 2019? 
RQ2 What is the general trend in open access publishing over disciplines among the most prestigious (Scopus Q1 ranked) journals between 2000 and 2019?

RQ3 What is the general trend in open access publishing over disciplines in different geographical regions between 2000 and 2019?

\section{Methods}

To answer our research questions, we collected data from Scimago Journal and Country Ranking that works with information from Elsevier's Scopus, the most inclusive international database of scientific publications. To analyze the global, regional and disciplinary distribution of open access journals over time, we have selected nine eminent subject areas, three time periods and seven world regions for further analysis. Time periods were selected in order to follow the development of open access publishing over the widest possible range, as Scimago currently offers data on journals between 2000 and 2019. Disciplines were selected in order to cover the highest possible variety of scholarly fields. Finally, world regions were selected as they are offered by Scimago. This categorization relates to geographical position instead of geopolitical or economic areas, thus Asia includes both developing regions as Malaysia or India as well as countries with developed economies such as Japan or Taiwan. Similarly, despite their strong academic relations to the U.S. and Europe, both Turkey and Israel fall into the group of Middle Eastern countries. Russia is considered as an Eastern European country, as well as some Central Asian countries such as Azerbaijan and Georgia, while Kazakhstan and Uzbekistan are considered as Asiatic countries (Table 1).

First, in order to catch global trends and to answer our first research question, we calculated the number of Scopus-indexed journals in each benchmark year in each discipline, and we calculated the amount of open access journals as well. In Scimago, the only journals considered as open access are those that provide either diamond open access publication (meaning that both publishing and reading papers is free of charge) or gold open access publication (with an article processing charge that unlocks access to published papers), whereas journals with hybrid, or green open access models are not considered as open access journals. Unfortunately, Scimago does not disclose which open access model a journal should use in order to be categorized as an open access journal. As a consequence, we had to test manually whether journals with diamond, gold, green or hybrid open access policies were categorized as open access journals. After running several checks on different fields, we found out that Scimago categorizes journals as open access journals only if open access publication is mandatory in them-whether for free, as in the case of the diamond models, or in exchange for author processing charges, as in the case of the gold model.

In line with earlier studies that found an association between journal prestige and the likelihood that the journal will use open access publication, we also calculated the number and proportion of open access journals in the first quartile (Q1) of the 
Table 1 Geographic and disciplinary construction of our sample

\begin{tabular}{|c|c|}
\hline \multirow[t]{9}{*}{ Disciplines } & Arts and humanities \\
\hline & $\begin{array}{l}\text { Business, management } \\
\text { and accounting }\end{array}$ \\
\hline & Computer science \\
\hline & Economics \\
\hline & Engineering \\
\hline & Neuroscience \\
\hline & Physics and astronomy \\
\hline & Psychology \\
\hline & Social sciences \\
\hline \multirow[t]{7}{*}{ Geographies } & Africa \\
\hline & Asia \\
\hline & Eastern Europe \\
\hline & Latin America \\
\hline & Middle East \\
\hline & North America \\
\hline & Western Europe \\
\hline \multirow[t]{3}{*}{ Years } & 2000 \\
\hline & 2010 \\
\hline & 2019 \\
\hline
\end{tabular}

Scimago list that contains the top $25 \%$ of journals in each discipline. Every year, Scimago conducts journal assessments and categorizes them into four quartiles on the basis of Scopus citations and the average citations per paper quotient [31].

To answer our second research question, we calculated the share of open access journals in each discipline and geographical location for each benchmark year. A minimum number of published journals was necessary for meaningful calculations; thus, when the number of journals in a given world region was less than ten, we indicated that the open access share for this specific discipline, world region and time period should be interpreted critically. Typically, this occurred in the case of Africa, the Middle East and Latin America, where sometimes only three or five Scopus-indexed journals were published in a given discipline.

\section{Results}

Table 2 shows the results of our calculations in detail. In 2000, the share of open access journals was under $10 \%$ in each discipline, with an average of $4.3 \%$. This grew to $15.3 \%$ in 2019 , meaning that the share of open access journals has tripled over the last two decades. However, the exact proportion of open access journals within the set of all the journals varies across different disciplines, with neuroscience having the highest open access ratio, and computer science with the lowest. Besides significant differences, the share of open access journals increased significantly from 2000 to 2019 in all the disciplines analyzed. 
Table 2 Proportion of open access journals across disciplines in our three benchmark years

\begin{tabular}{|c|c|c|c|c|c|}
\hline \multirow[t]{2}{*}{ Year } & & & \multicolumn{2}{|l|}{ Open access } & \multirow[t]{2}{*}{ Total } \\
\hline & & & Not open access & Open access & \\
\hline \multirow[t]{21}{*}{2000} & \multicolumn{5}{|l|}{ Discipline } \\
\hline & \multirow[t]{2}{*}{ Arts and humanities } & Count & 1358 & 69 & 1427 \\
\hline & & $\%$ within discipline & $95.2 \%$ & $4.8 \%$ & $100.0 \%$ \\
\hline & \multirow{2}{*}{$\begin{array}{l}\text { Business, management and } \\
\text { accounting }\end{array}$} & Count & 796 & 20 & 816 \\
\hline & & $\%$ within discipline & $97.5 \%$ & $2.5 \%$ & $100.0 \%$ \\
\hline & \multirow[t]{2}{*}{ Computer science } & Count & 1183 & 51 & 1234 \\
\hline & & $\%$ within discipline & $95.9 \%$ & $4.1 \%$ & $100.0 \%$ \\
\hline & \multirow[t]{2}{*}{ Economics } & Count & 451 & 13 & 464 \\
\hline & & $\%$ within discipline & $97.2 \%$ & $2.8 \%$ & $100.0 \%$ \\
\hline & \multirow[t]{2}{*}{ Engineering } & Count & 2786 & 93 & 2879 \\
\hline & & $\%$ within discipline & $96.8 \%$ & $3.2 \%$ & $100.0 \%$ \\
\hline & \multirow[t]{2}{*}{ Neuroscience } & Count & 333 & 17 & 350 \\
\hline & & $\%$ within discipline & $95.1 \%$ & $4.9 \%$ & $100.0 \%$ \\
\hline & \multirow[t]{2}{*}{ Physics and astronomy } & Count & 838 & 58 & 896 \\
\hline & & $\%$ within discipline & $93.5 \%$ & $6.5 \%$ & $100.0 \%$ \\
\hline & \multirow[t]{2}{*}{ Psychology } & Count & 771 & 17 & 788 \\
\hline & & $\%$ within discipline & $97.8 \%$ & $2.2 \%$ & $100.0 \%$ \\
\hline & \multirow[t]{2}{*}{ Social sciences } & Count & 2758 & 163 & 2921 \\
\hline & & $\%$ within discipline & $94.4 \%$ & $5.6 \%$ & $100.0 \%$ \\
\hline & \multirow[t]{2}{*}{ Total } & Count & 11,274 & 501 & 11,775 \\
\hline & & $\%$ within discipline & $95.7 \%$ & $4.3 \%$ & $100.0 \%$ \\
\hline 2010 & Discipline & & & & \\
\hline
\end{tabular}


Table 2 (continued)

Discipline * Open access * Year crosstabulation

\begin{tabular}{|c|c|c|c|c|c|}
\hline \multirow[t]{2}{*}{ Year } & & & \multicolumn{2}{|l|}{ Open access } & \multirow[t]{2}{*}{ Total } \\
\hline & & & Not open access & Open access & \\
\hline \multirow{2}{*}{\multicolumn{2}{|c|}{ Arts and humanities }} & Count & 2834 & 255 & 3089 \\
\hline & & $\%$ within discipline & $91.7 \%$ & $8.3 \%$ & $100.0 \%$ \\
\hline \multirow{2}{*}{\multicolumn{2}{|c|}{$\begin{array}{l}\text { Business, management and } \\
\text { accounting }\end{array}$}} & Count & 1390 & 83 & 1473 \\
\hline & & $\%$ within discipline & $94.4 \%$ & $5.6 \%$ & $100.0 \%$ \\
\hline \multirow{2}{*}{\multicolumn{2}{|c|}{ Computer science }} & Count & 6352 & 167 & 6519 \\
\hline & & $\%$ within discipline & $97.4 \%$ & $2.6 \%$ & $100.0 \%$ \\
\hline \multirow{2}{*}{\multicolumn{2}{|c|}{ Economics }} & Count & 872 & 27 & 899 \\
\hline & & $\%$ within discipline & $97.0 \%$ & $3.0 \%$ & $100.0 \%$ \\
\hline \multirow{2}{*}{\multicolumn{2}{|c|}{ Engineering }} & Count & 5909 & 287 & 6196 \\
\hline & & $\%$ within discipline & $95.4 \%$ & $4.6 \%$ & $100.0 \%$ \\
\hline \multirow{2}{*}{\multicolumn{2}{|c|}{ Neuroscience }} & Count & 406 & 105 & 511 \\
\hline & & $\%$ within discipline & $79.5 \%$ & $20.5 \%$ & $100.0 \%$ \\
\hline \multirow{2}{*}{\multicolumn{2}{|c|}{ Physics and astronomy }} & Count & 1354 & 131 & 1485 \\
\hline & & $\%$ within discipline & $91.2 \%$ & $8.8 \%$ & $100.0 \%$ \\
\hline \multirow{2}{*}{\multicolumn{2}{|c|}{ Psychology }} & Count & 982 & 91 & 1073 \\
\hline & & $\%$ within discipline & $91.5 \%$ & $8.5 \%$ & $100.0 \%$ \\
\hline \multirow{2}{*}{\multicolumn{2}{|c|}{ Social sciences }} & Count & 4824 & 557 & 5381 \\
\hline & & $\%$ within discipline & $89.6 \%$ & $10.4 \%$ & $100.0 \%$ \\
\hline \multirow{2}{*}{\multicolumn{2}{|c|}{ Total }} & Count & 24,923 & 1703 & 26,626 \\
\hline & & $\%$ within discipline & $93.6 \%$ & $6.4 \%$ & $100.0 \%$ \\
\hline $2019 I$ & Discipline & & & & \\
\hline
\end{tabular}


Table 2 (continued)

\begin{tabular}{|c|c|c|c|c|}
\hline \multirow[t]{2}{*}{ Year } & & \multicolumn{2}{|l|}{ Open access } & \multirow[t]{2}{*}{ Total } \\
\hline & & Not open access & Open access & \\
\hline \multirow[t]{2}{*}{ Arts and humanities } & Count & 3704 & 791 & 4495 \\
\hline & $\%$ within discipline & $82.4 \%$ & $17.6 \%$ & $100.0 \%$ \\
\hline \multirow{2}{*}{$\begin{array}{l}\text { Business, management and } \\
\text { accounting }\end{array}$} & Count & 1451 & 206 & 1657 \\
\hline & $\%$ within discipline & $87.6 \%$ & $12.4 \%$ & $100.0 \%$ \\
\hline \multirow[t]{2}{*}{ Computer science } & Count & 3739 & 377 & 4116 \\
\hline & $\%$ within discipline & $90.8 \%$ & $9.2 \%$ & $100.0 \%$ \\
\hline \multirow[t]{2}{*}{ Economics } & Count & 959 & 201 & 1160 \\
\hline & $\%$ within discipline & $82.7 \%$ & $17.3 \%$ & $100.0 \%$ \\
\hline \multirow[t]{2}{*}{ Engineering } & Count & 4266 & 577 & 4843 \\
\hline & $\%$ within discipline & $88.1 \%$ & $11.9 \%$ & $100.0 \%$ \\
\hline \multirow[t]{2}{*}{ Neuroscience } & Count & 438 & 158 & 596 \\
\hline & $\%$ within discipline & $73.5 \%$ & $26.5 \%$ & $100.0 \%$ \\
\hline \multirow[t]{2}{*}{ Physics and astronomy } & Count & 1301 & 213 & 1514 \\
\hline & $\%$ within discipline & $85.9 \%$ & $14.1 \%$ & $100.0 \%$ \\
\hline \multirow[t]{2}{*}{ Psychology } & Count & 1100 & 203 & 1303 \\
\hline & $\%$ within discipline & $84.4 \%$ & $15.6 \%$ & $100.0 \%$ \\
\hline \multirow[t]{2}{*}{ Social sciences } & Count & 5848 & 1452 & 7300 \\
\hline & $\%$ within discipline & $80.1 \%$ & $19.9 \%$ & $100.0 \%$ \\
\hline \multirow[t]{2}{*}{ Total } & Count & 22,806 & 4178 & 26,984 \\
\hline & $\%$ within discipline & $84.5 \%$ & $15.5 \%$ & $100.0 \%$ \\
\hline
\end{tabular}

However, the growing prevalence of open access journals followed different trends in each discipline (Fig. 1). The most striking growth was seen in neuroscience: in 2019, the share of open access journals was five times greater than two decades earlier, and now the proportion of open access journals is over $25 \%$. A similar pace of growth was characteristic of economics, where the share of open access journals was $17.3 \%$ in 2019 , as contrasted with the $2.8 \%$ in 2000 . Generally, we can see three trends. First, there are disciplines in which the most striking growth happened between 2000 and 2010, as in the case of neuroscience and psychology. Second, there are scholarly fields where the most important emergence in the proportion of open access journals occurred in the last ten years, like in computer science, economics, engineering and social sciences. Finally, in arts and humanities, business, management and accounting, physics and astronomy, 


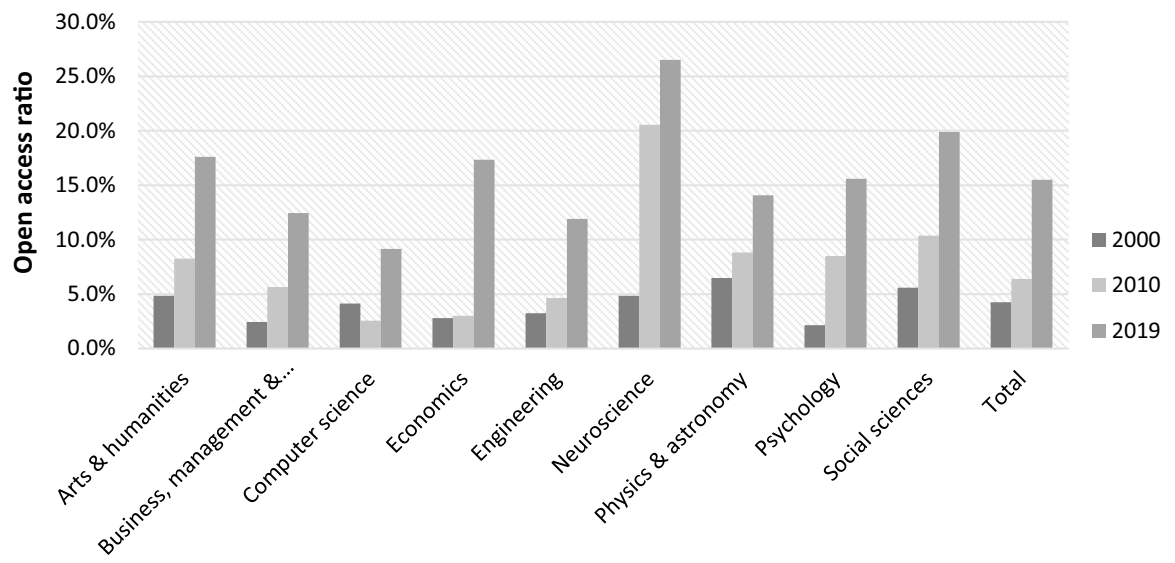

Fig. 1 Development of the proportion of open access journals, 2000-2019

the pace of the evolution of open access publication models has been consistent over the last two decades.

To address our second research question, we further analyzed our sample to look for publication patterns among the Q1 journals. Within the set of Q1 journals, it is only in the field of neuroscience that the emergence in the number of Q1 journals is equal to the emergence in the number of all open access journals (Fig. 2). Indeed, the share of open access Q1 journals is $26.5 \%$ in 2019, which is even slightly higher than the share of all open access journals in neuroscience. However, in other

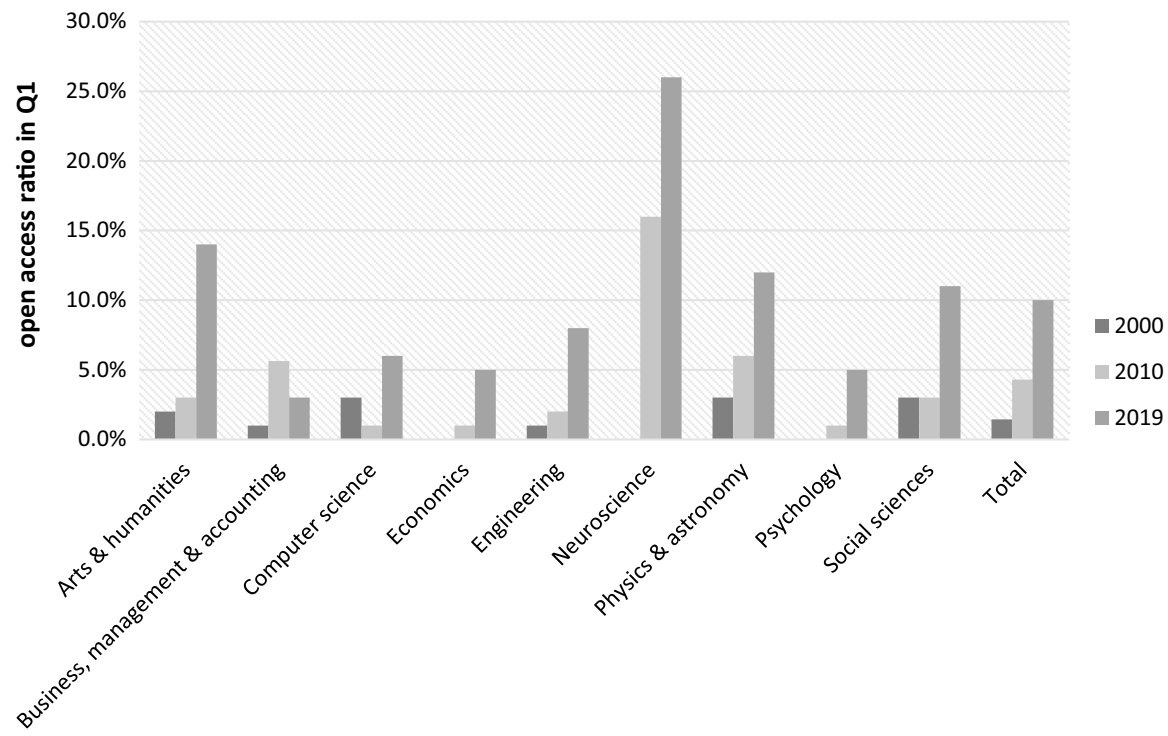

Fig. 2 Development of the proportion of Q1-ranked open access journals, 2000-2019 
disciplines, the growth of highly ranked open access journals underperforms the general growth, and in four of the nine disciplines, the share of open access Q1 journals from all Q1 journals has not exceeded 5\%. This difference between the general trend and the trend of the top ranked journals shows that open access publication is more characteristic of lower ranked journals.

Moreover, there is a strong, statistically significant correlation between the proportion of open access journals among all the published journals and the proportion of Q1 open access journals $(r=0.889 p<0.001)$, and we found a significant regression equation predicting the proportion of Q1 open access journals based on the proportion of open access journals in the set of all published journals $(\mathrm{F}(1$, $28)=105.995, p<0.001$ ), with an $R^{2}$ of 0.791 . However, the proportion of open access journals in the Q1 quartile was lower than the general proportion of open access journals in each discipline and time period, and the growth in the proportion of open access journals was also lower than in the general trend (Table 3).

To address our third research question, we analyzed the geographical distribution of open access papers over three benchmark years and nine disciplines. We found that the overall proportion of open access journals was the lowest in Northern America and Western Europe, while in Latin America, the open access model of publishing is the standard. The general trend also shows that the share of open access journals increased significantly in every world region (Fig. 3).

Significant disciplinary differences were found when we calculated the proportion of open access journals across regions and disciplines (Table 4). The share of

Table 3 General proportion of open access journals and proportion of open access journals in the Q1 quartile

\begin{tabular}{|c|c|c|c|c|}
\hline & & 2000 & 2010 & 2019 \\
\hline \multirow[t]{2}{*}{ Arts and humanities } & $\mathrm{OA}$ (general) $\%$ & 5 & 8 & 18 \\
\hline & $\mathrm{OA}(\mathrm{Q} 1) \%$ & 2 & 3 & 14 \\
\hline \multirow[t]{2}{*}{ Business... } & $\mathrm{OA}$ (general) $\%$ & 2 & 6 & 12 \\
\hline & $\mathrm{OA}(\mathrm{Q} 1) \%$ & 1 & 2 & 3 \\
\hline \multirow[t]{2}{*}{ Computer science } & $\mathrm{OA}$ (general) $\%$ & 4 & 3 & 9 \\
\hline & $\mathrm{OA}(\mathrm{Q} 1) \%$ & 3 & 1 & 6 \\
\hline \multirow[t]{2}{*}{ Economics... } & OA (general) $\%$ & 3 & 9 & 17 \\
\hline & $\mathrm{OA}(\mathrm{Q} 1) \%$ & 0 & 1 & 5 \\
\hline \multirow[t]{2}{*}{ Engineering } & OA (general) $\%$ & 3 & 5 & 12 \\
\hline & $\mathrm{OA}(\mathrm{Q} 1) \%$ & 1 & 2 & 8 \\
\hline \multirow[t]{2}{*}{ Neuroscience } & $\mathrm{OA}$ (general) $\%$ & 5 & 20 & 28 \\
\hline & $\mathrm{OA}(\mathrm{Q} 1) \%$ & 0 & 16 & 26 \\
\hline \multirow[t]{2}{*}{ Physics and astronomy } & OA (general) $\%$ & 6 & 9 & 14 \\
\hline & $\mathrm{OA}(\mathrm{Q} 1) \%$ & 3 & 6 & 12 \\
\hline \multirow[t]{2}{*}{ Psychology } & OA (general) $\%$ & 2 & 8 & 18 \\
\hline & $\mathrm{OA}(\mathrm{Q} 1) \%$ & 0.5 & 1 & 5 \\
\hline \multirow[t]{2}{*}{ Social science } & OA (general) \% & 6 & 10 & 20 \\
\hline & $\mathrm{OA}(\mathrm{Q} 1) \%$ & 3 & 3 & 11 \\
\hline \multirow[t]{2}{*}{ All } & $\mathrm{OA}$ (general) \% & 6 & 11 & 20 \\
\hline & $\mathrm{OA}(\mathrm{Q} 1) \%$ & 3 & 6 & 16 \\
\hline
\end{tabular}




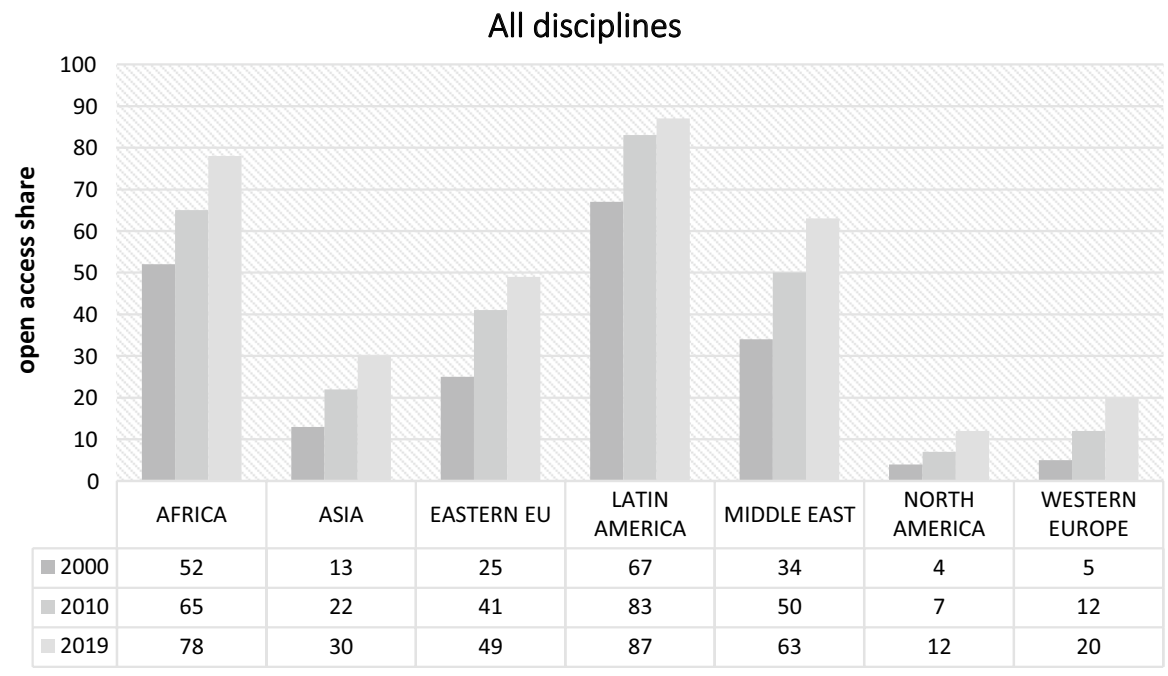

Fig. 3 General trends in open access publications broken down by world regions

open access journals in North America is still minimal in seven out of the nine disciplines, and there are two scholarly fields in Western Europe with less than $10 \%$ of journals being open access. It is followed by Asia with a considerably higher frequency of open access journals in all disciplines, while in Latin America the proportion of open access journals varies from 70 to $90 \%$ across disciplines. Apart from those cases where the number of journals was not sufficient to calculate open access ratios, the share of open access journals increased significantly over time across all locations and disciplines.

Since there were significant differences between the number of published journals across disciplines and world regions, we also calculated if the total number of published journals correlated with the proportion of open access journals. Indeed, we found that the total number of published journals has a significant negative correlation $(r=-.420, p<0.01)$ with the proportion of open access journals. To explore the exact nature of this connection, we ran a linear regression predicting open access proportion from the number of published journals. A significant regression equation was found $(\mathrm{F}(1,187)=40.073, p<0.001)$, with an $R^{2}$ of 0.176 . Thus, open access journals are more prevalent in those cases where the number of all the published journals is lower. However, the significant negative association between the number of journals and the share of open access journals can be explained in the following ways. First, it is possible that the number of journals published is directly related to the proportion of open access journals, and, since there are more journals in Western Europe and North America than in other parts of the world, the lower proportion of open access journals in Western Europe and North America is a consequence of their abundance of journals, and not a result of their publishing policies. Second, it is also possible that world regions differ in both the number of their published journals and in their open access policies. In order to decide which suggestion fits our data better, we analyzed whether the negative association between the number 


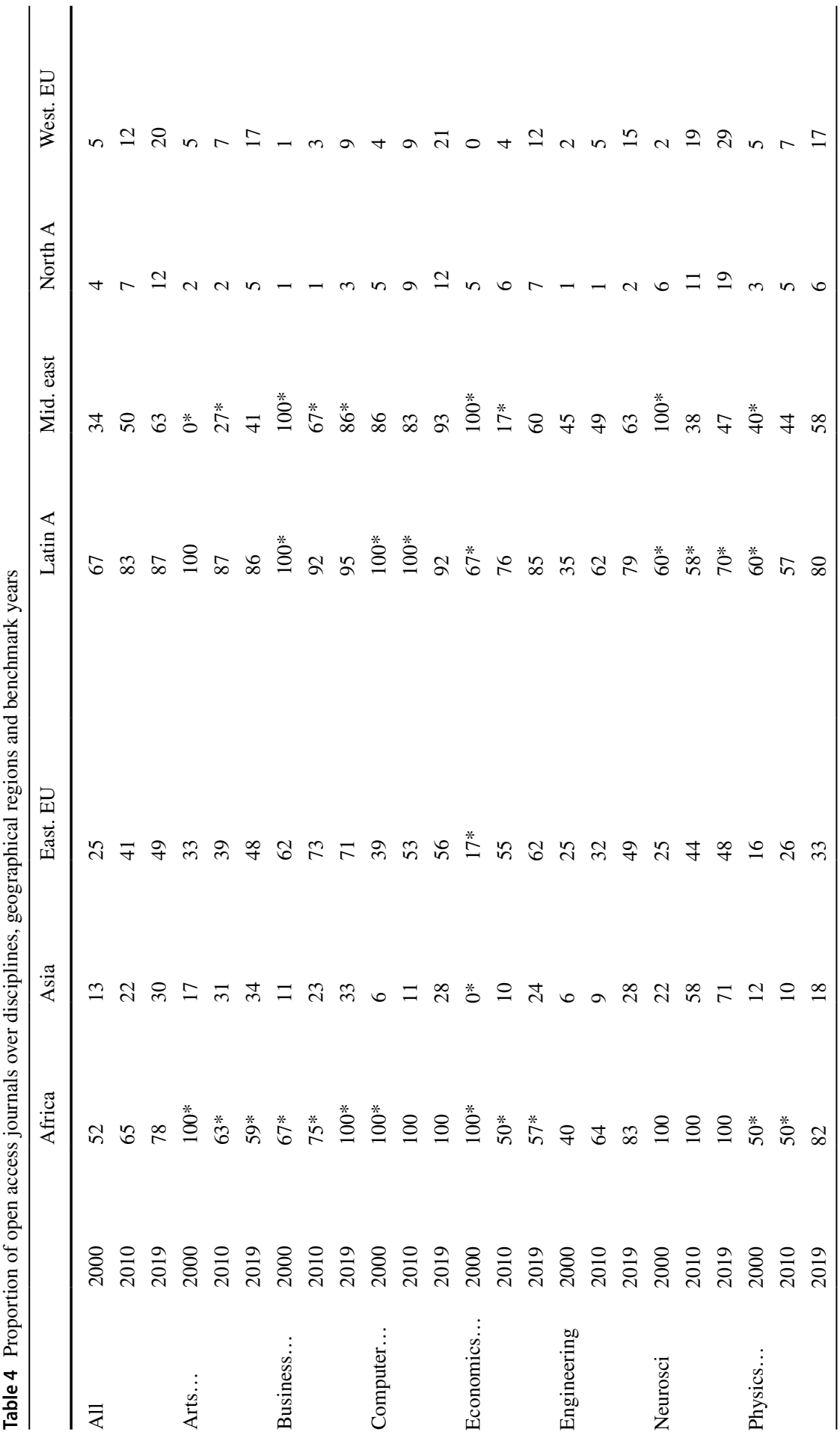




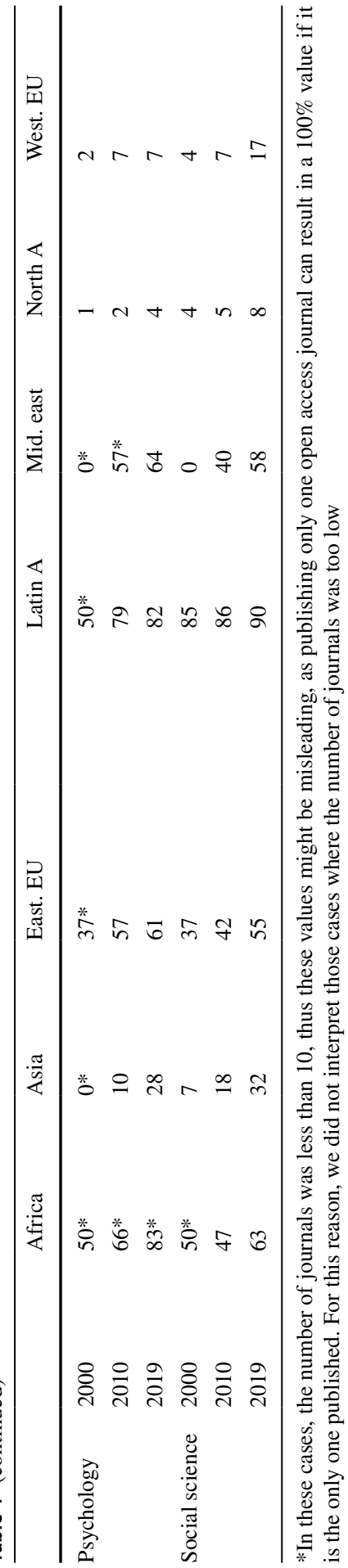


of all published journals and the number of open access journals occurs in both the world regions with many journals (Western Europe and Northern American) and in world regions with less journals (Africa, Asia, Eastern Europe, Latin America and the Middle East). As Table 5 shows, North America and Western Europe together account for approximately $80 \%$ of the journals published in all disciplines.

In Western Europe and North America, there is no statistically significant relation between the number of all journals and the proportion of open access journals $(p=346)$, while in other world regions, there is a statistically significant negative association between the number of published journals and the proportion of them that are open access $(r=-0.262, p<0.01)$. Moreover, a statistically significant regression equation was found $(\mathrm{F}(1,133)=9.073, p<0.01)$, with an $R^{2}$ of 0.062 that predicts the proportion of open access journals from the number of all published journals. Thus, we found that the negative association between the number of journals and the proportion of open access publication occurs only in the cases of nonWestern world regions, and is not characteristic of Western publishers. It follows that the ratio of open access journals cannot be explained by the number of published journals alone, and both disciplinary differences and open access policies that are characteristic of different world regions should be considered as well.

\section{Discussion and Conclusions}

In line with the relevant literature, our research found that the proportion of open access journals has shown a significant increase since the early 2000s [25, 38], and we found that this phenomenon appeared across all disciplines and world regions. Our first research question was related to the general trend of the change in the proportion of open access journals over the last two decades. We found that the need for open access publication [26] resulted in a significant growth in the proportion of open access journals up until 2010, when the share of open access journals increased from 4 to $6 \%$, but the real skyrocketing of open access model occurred only over the last ten years. Currently, more than $15 \%$ of Scopus-indexed journals are published on an open access basis. Despite significant disciplinary differences,

Table 5 Share of world regions in the total of published journals, 2019

\begin{tabular}{llll}
\hline & Others & North America & $\begin{array}{l}\text { Western } \\
\text { Europe }\end{array}$ \\
\hline Arts and humanities & 19 & 22 & 59 \\
Business... & 16 & 29 & 55 \\
Computer science & 17 & 61 & 22 \\
Economics... & 19 & 22 & 59 \\
Engineering & 21 & 48 & 31 \\
Neuroscience & 15 & 32 & 53 \\
Physics and astronomy & 22 & 41 & 37 \\
Psychology & 13 & 40 & 47 \\
Social science & 18 & 27 & 55 \\
\hline
\end{tabular}


this general trend holds for all the research fields analyzed, and while in 2000, there were disciplines with a share of open access publication close to zero, now there are no research fields with less than $10 \%$ of journals being open access.

Our second research question was related to the prestige of journals, thus we analyzed whether there were significant differences between the open access proportion of all the journals and the open access proportion of Q1-ranked journals. We found that, with the exception of neuroscience, the growth in the proportion of Q1 journals was lower than the general trend, and the proportion of open access journals was lower than it was among all the journals in each benchmark year. We can offer at least three explanations for this phenomenon. According to the first, we assume that, since most Q1 journals are older than the newcomers in lower quartiles [18], their business models were developed before the historical period where open access became more important. Of course, these older journals usually offer hybrid, gold or green open access possibilities [13], but these are nothing more that the extensions of existing publication models $[5,12]$. By contrast, both diamond open access and gold open access are fundamentally new, and thus require totally different business models [3]. In the case of the diamond models, there is typically a non-profit maintenance entity such as a university or academic association [14]. Second newer journals that typically still lack a scholarly reputation and prestige have to offer appealing possibilities that make themselves competitive alongside the older established journals in the field. As several studies demonstrate that open access publication can significantly increase both readership and impact [40, 41], and given that author processing charges in non-diamond open access models can be extremely high [13], diamond open access can be a highly appealing feature in a new journal, and one that can attract the attention of both authors and readers. Thirdly, non-Western world regions, most typically Latin America, usually have pro-open access publishing systems, but since they are relative newcomers to international academia, their journals are still ranked lower than their Western counterparts. Thus, the lower ratio of open access journals in the Q1 quartile can be also explained by geopolitical differences.

Our third research question aimed to explore the geographical differences of open access publications over the disciplines analyzed. We found that the proportion of open access journals was the lowest in the so-called developed world (with the lowest rates in North America, followed by Western Europe), with higher proportions in Asia, and Latin America having the greatest open access ratio. This general trend is characteristic of all research fields, and disciplinary differences typically occur only in Western Europe and North America, while there are no significant differences 
in the proportion of open access journals across disciplines in non-Western world regions. In the case of North American journals, open access ratio can be extremely low even today: only $2 \%$ of engineering journals, $3 \%$ of business, management and accounting journals and $4 \%$ of psychology journals were published on an open access basis in 2019. The proportion of open access journals is significantly higher in other areas such as social sciences (8\%), computer science (12\%) and neuroscience (19\%). There are considerable differences between disciplines in Western Europe as well, as there are research fields with relatively low proportions of open access publication, such as psychology (7\%), or business, management and accounting (9\%), and disciplines with high open access ratios like computer science (21\%) and neuroscience (29\%). In sum, we found that disciplinary differences in open access ratio occurs only in the Western world, which means that we should consider both geography and discipline in the explanation of open access trends. Thus, our model that aims to interpret open access trajectories over different disciplines, world regions, prestige factors and time periods should consider the following variables (Table 6).

Considering them as vectors that affect the proportion of open access journals, our model offers these five variables to interpret existing open access trends, from which three (but not the same three) variables apply to: (a) all regions, (b) Western and (c) non-Western geographies (Fig. 4).

\section{Limitations}

The most important limitation of our research is a consequence of the fact that Scimago does not use different categories for diamond and gold open access journals. Accordingly, we could not make conclusive statements on the business models themselves, for although open access publication is mandatory in both cases, the diamond and gold open access models are based on fundamentally different business strategies [4, 13]. Further research with a specific focus on the differences between the gold and diamond models should manually code a representative set of journals and apply different categories for each model. While we can reasonably assume that Western European and North American countries with giant commercial publishing houses are more likely follow the gold model, and that non-Western universitybased publishers will tend to follow the diamond model, an in-depth empirical analysis should identify the exact proportions across disciplines and world regions. 


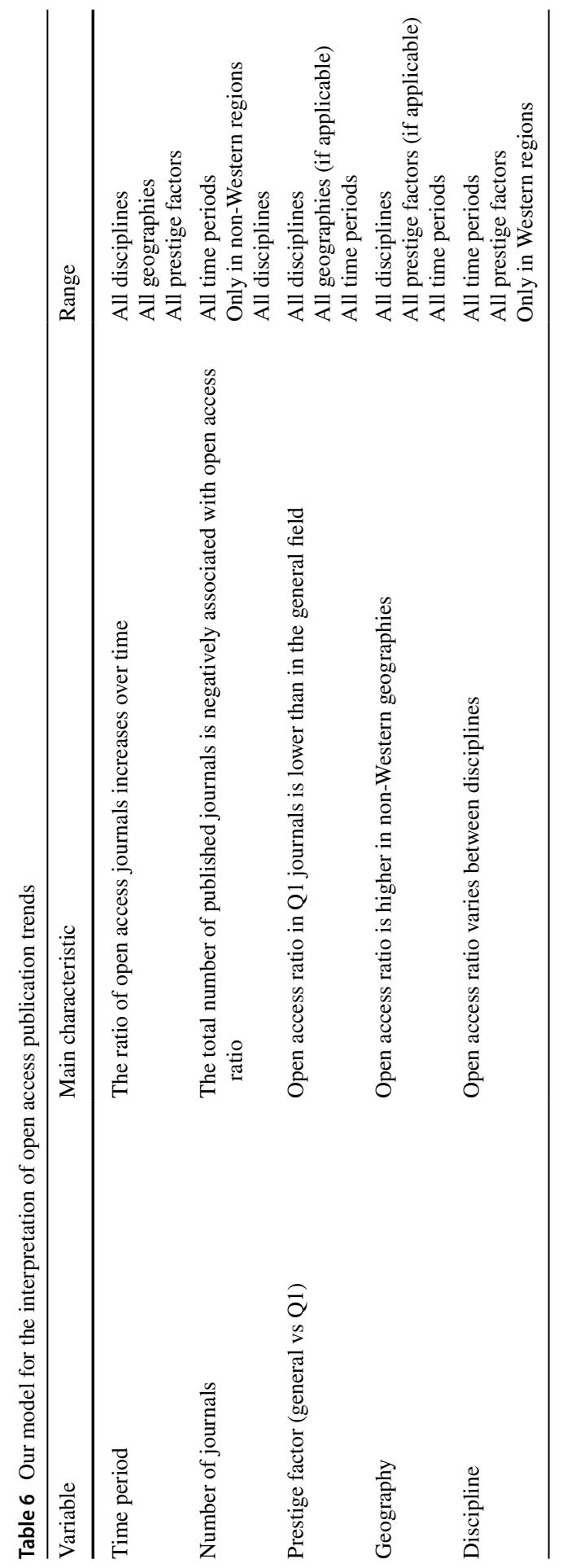




\section{GENERAL FIELD}

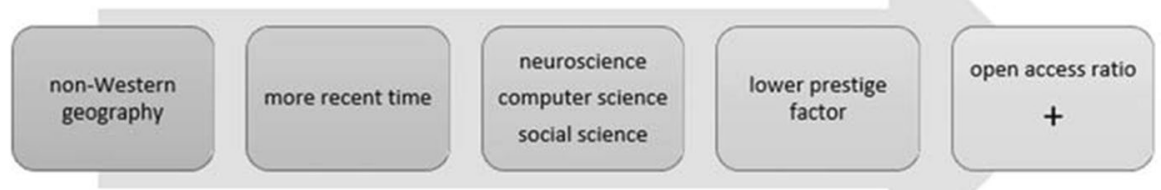

\section{WESTERN GEOGRAPHIES}

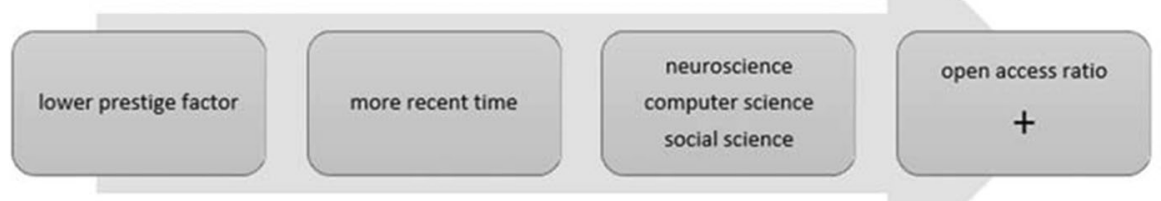

\section{NON-WESTERN GEOGRAPHIES}

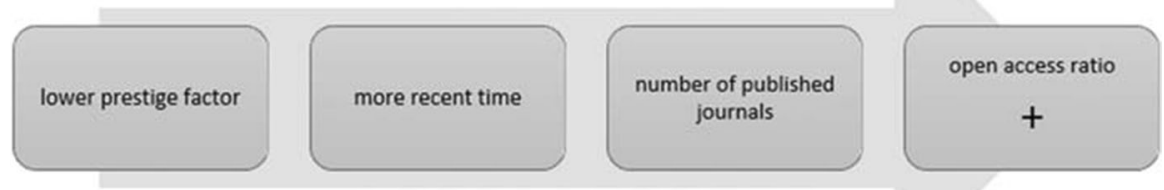

Fig. 4 Vectors explaining open access ratio on the general field, in Western and non-Western geographies

Funding Open access funding provided by National University of Public Service.

Open Access This article is licensed under a Creative Commons Attribution 4.0 International License, which permits use, sharing, adaptation, distribution and reproduction in any medium or format, as long as you give appropriate credit to the original author(s) and the source, provide a link to the Creative Commons licence, and indicate if changes were made. The images or other third party material in this article are included in the article's Creative Commons licence, unless indicated otherwise in a credit line to the material. If material is not included in the article's Creative Commons licence and your intended use is not permitted by statutory regulation or exceeds the permitted use, you will need to obtain permission directly from the copyright holder. To view a copy of this licence, visit http://creativecommons.org/licen ses/by/4.0/. 


\section{References}

1. Arthur P. Nikos Koutras: Building equitable access to knowledge through open access repositories. Publ Res Q. 2020;36:681-3.

2. Bidarra J, Sousa N. Implementing mobile learning within personal learning environments: a study of two online courses. Int Rev Res Open Distrib Learn. 2020;21(4):181-98.

3. Björk BC. Gold, green, and black open access. Learn Publ. 2017;30(2):173-5.

4. Björk BC. Growth of hybrid open access, 2009-2016. PeerJ. 2017;5:e3878. https://doi.org/10. 7717/peerj.3878.

5. Björk BC, Laakso M, Welling P, Paetau P. Anatomy of green open access. J Assoc Inf Sci Technol. 2013;65(2):237-50.

6. Bohannon J. Who's afraid of peer review? Science. 2013;6154:60-5.

7. Brainard J. Scientific societies worry about threat from plan. Science. 2019;6425:332-3.

8. Clark J, Smith R. Firm action needed on predatory journals. BMJ. 2015;350:h210.

9. Contreras JL. Open access scientific publishing and the developing world [Internet]. Social Science Research Network, Rochester. https://papers.ssrn.com/abstract=2065887 (2012).

10. Cummings S, Heeks R, Huysman M. Knowledge and learning in online communities in development: a social capital perspective. Development informatics working paper series, Paper no 16. 2003.

11. De Castro P, Salinetti S. Quality of grey literature in the open access era: privilege and responsibility. Publ Res Q. 2004;20:4-12.

12. Demeter M. Open access movements: emancipation or hypocrisy? KOME Int J Pure Commun Inq. 2019;7(1):126-7.

13. Demeter M, Istratii R. Scrutinising what open access journals mean for global inequalities. Publ Res Q. 2020;36:505-22.

14. Demeter M, Goyanes M, Mellado C, Navarro F, Mihalik J. The Ibero-Americanization of communication studies through scholarly and linguistic expansion. 2021 (forthcoming).

15. Ejikeme AN, Ezema IJ. The potentials of open access initiative and the development of institutional repositories in Nigeria: implications for scholarly communication. Publ Res Q. 2019;35:6-21.

16. Fuchs C, Sandoval M. The diamond model of open access publishing: Why policy makers, scholars, universities, libraries, labour unions and the publishing world need to take non-commercial, nonprofit open access serious. TripleC Commun Capital Crit. 2013;11(2):428-43.

17. García-Peñalvo FJ. Publishing in open access. J Inf Technol Res. 2017;10(3):6-8.

18. Goyanes M, Demeter M. How the geographic diversity of editorial boards affects what is published in JCR-ranked communication journals. J Mass Commun Q. 2020;97(4):1123-48. https://doi.org/ 10.1177/1077699020904169.

19. Harnad S, Brody T, Vallières F, Carr L, Hitchcock S, Gingras Y, Hilf ER, et al. The access/impact problem and the green and gold roads to open access. Ser Rev. 2004;30(4):310-4.

20. Haug CJ. No free lunch-what price Plan S for scientific publishing? N Engl J Med. 2019;380:1181-5.

21. Istratii R, Demeter M. Plan S and the 'opening up' of scientific knowledge: a critical commentary. Decolonial Subversions. 2020;1(1):13-21.

22. Iyandemye J, Thomas MP. Low income countries have the highest percentages of open access publication: a systematic computational analysis of the biomedical literature. PLoS ONE. 2019;14(7):e0220229. https://doi.org/10.1371/journal.pone.0220229.

23. Jarvis P. The Routledge international handbook of lifelong learning. Oxon: Routledge; 2009.

24. Kingsley D (2013) Busting the top five myths about open access publishing. The Conversation. http://theconversation.com/busting-the-top-five-myths-about-open-access-publishing-14792.

25. Koutras N. The open access in the context of the globalizing world. Publ Res Q. 2015;31:132-41.

26. Koutras N. Open access publishing in the European Union: the example of scientific works. Publ Res Q. 2020;36:418-36.

27. Koutras N. Building equitable access to knowledge through open access repositories. Hershey: IGI Global; 2020.

28. Knöchelmann M. The democratisation myth: open access and the solidification of epistemic injustices. SocArXiv. 2020. https://doi.org/10.31235/osf.io/hw7at. 
29. Laakso M. Green open access policies of scholarly journal publishers: a study of what, when, and where self-archiving is allowed. Scientometrics. 2014;99:475-94. https://doi.org/10.1007/ s11192-013-1205-3.

30. Laakso M, Björk BC. Hybrid open access—a longitudinal study. J Informetr. 2016;10(4):919-32.

31. Mañana-Rodríguez J. A critical review of SCImago Journal \& Country Rank. Res Eval. 2014;24(4):343-54.

32. Max Planck Society. Berlin declaration on open access to knowledge in the sciences and humanities. https://openaccess.mpg.de/Berlin-Declaration (2003).

33. McVeigh ME. Open access journals in the ISI citation databases: analysis of impact factors and citation patterns. https://ips.clarivate.com//m/pdfs/openaccesscitations2.pdf (2019)

34. National Science Board. Science and Engineering Indicators (2018). National Science Foundation, Alexandria. https://www.nsf.gov/statistics/indicators/ (2018).

35. Normand S. Is diamond open access the future of open access? IJ Grad Stud J Fac Inf. 3(2). https:// theijournal.ca/index.php/ijournal/article/view/29482 (2018)

36. Piwowar H, Priem J, Larivière V, Alperin JP, Matthias L, Norlander B, et al. The state of OA: a largescale analysis of the prevalence and impact of Open Access articles. PeerJ https://www.ncbi.nlm. nih.gov/pmc/articles/PMC5815332/ (2018)

37. Reeves C. The wellcome trust, eLS. Wiley; 2001. https://doi.org/10.1002/9780470015902.a0003 554.

38. Schiltz M. Science without publication paywalls: cOAlition S for the realisation of full and immediate open access. PLoS Biol. 2018;16(9):e3000031. https://doi.org/10.1371/journal.pbio.3000031.

39. Science Europe. Science Europe principles on open access to research publications. 2013. (updated May 2015). http://scieur.org/opennew. Cited 29 Aug 2018.

40. Tennant JP, Waldner F, Jacques DC, Masuzzo P, Collister LB, Hartgerink CHJ. The academic, economic and societal impacts of Open Access: an evidence-based review. F1000Res. 2019. https:// www.ncbi.nlm.nih.gov/pmc/articles/PMC4837983

41. Xia JA. Preliminary study of alternative open access journal indexes. Publ Res Q. 2019;35:274-84.

42. Waithaka MW, Onyancha OB. Use of open access channels for scholarly publishing in Kenyan universities. Publ Res Q. 2021. https://doi.org/10.1007/s12109-021-09795-9(advanceonlinepublica tion).

43. Willinsky J. The access principle: the case for open access to research and scholarship. Cambridge: The MIT Press; 2005.

44. Willinsky J. The unacknowledged convergence of open source, open access, and open science. First Monday. 2005. http://firstmonday.org/ojs/index.php/fm/article/view/1265

45. Wolpert AJ. For the sake of inquiry and knowledge - the inevitability of open access. N Engl J Med. 2013;368(9):785-7.

Publisher's Note Springer Nature remains neutral with regard to jurisdictional claims in published maps and institutional affiliations. 